\title{
Recapturing place identification through community heritage marketing
}

Matthew Alexander

Kathy Hamilton*

Department of Marketing

Stenhouse Building

University of Strathclyde

173 Cathedral Street

G4 ORQ Glasgow, UK

FAX: +44(0) 1415522802

kathy.hamilton@strath.ac.uk Tel: +44(0) 1415483240

matthew.j.alexander@strath.ac.uk Tel: +44(0) 1415483949

*Denotes corresponding author

Acknowledgments - We wish to thank John Yellowlees from First ScotRail for his unstinting support of the project. The views in the paper are those of the authors and do not necessarily represent the perspective of ScotRail. 


\begin{abstract}
Purpose:

We are guided by the following research questions: How do community residents contribute to place marketing strategies that promote the heritage of their local area? How can community participation be encouraged and supported?

Design/methodology/approach:

We draw on an ethnographic study of adopted railway stations in Scotland. We use indepth interviews, participant observation alongside visual and archival data.
\end{abstract}

Findings:

We present and discuss three themes: community involvement in heritage activities, facilitating community participation through Adopt a Station and benefits and place identification.

Research implications:

Initiatives which empower residents should be prioritised to capitalise on their latent knowledge, skills and expertise. We suggest that bringing heritage outside the museum space into key places used by local residents will support the increased accessibility of heritage.

Originality/value:

While there are often strong arguments in favour of local community involvement in place marketing, it is much less common to find successful reports of this working in practice. Research either questions the capabilities of local residents to make meaningful contributions or hints at a tokenistic form of involvement. We contribute by offering insight into successful heritage-based community activity. Unlike previous research which focuses on the economic impact of place marketing, we focus on place identification for local residents. We also observe how offering a sense of ownership and freedom allows community management of the heritage message to flourish.

Keywords: place marketing, heritage marketing, community.

Classification: Research paper 


\section{Recapturing place identification through community heritage marketing}

Heritage marketing has received increasing attention in recent decades with a particular focus on the commodification and branding of heritage attractions for tourists (Goulding, 2000; Park, 2010; Chen and Chen, 2010). Given this emphasis on attracting visitors from outside to consume heritage, planning and delivery tends to be controlled at a corporate level with an accompanying economic bias (Ashworth and Graham, 2005). The result is a tension between market and consumer needs and it is perhaps unsurprising that paying visitors are prioritised over the local community (Aas et al. 2005; Kirshenblatt-Gimlet, 2006). There are strong calls for local residents and diverse producers of heritage to be involved in heritage planning processes (Teo and Yeoh, 1997; Timothy and Boyd, 2003; Ashworth and Graham, 2005) but studies which show how community involvement works in practice are absent. We address this gap and focus on a successful example of a community engagement scheme. We explore how community involvement can support and enhance the marketing of local heritage and are guided by the following research questions: How do community residents contribute to heritage marketing strategies that represent their local area? How does community involvement in heritage marketing encourage place identification? How can organisations facilitate community participation in heritage marketing?

We use the context of "Adopt a Station," a community engagement scheme offered by First ScotRail, holders of the rail franchise in Scotland. The scheme has been previously discussed in relation to customer engagement behaviours (Jaakkola and Alexander, 2014) and community involvement in tourism promotion through the creation of tourist gateways at stations (Hamilton and Alexander, 2013). In this paper, we complement the tourism 
perspective with a focus on heritage marketing in small towns and villages where it can make a strong contribution to place identity. We provide an example of community participation in the integration of heritage into railway stations, often an important community hub for a small town or village. Before describing the context of our research on Adopt a Station, we now turn to relevant literature on heritage, heritage and place marketing and community involvement in heritage marketing to provide the conceptual background to our study.

\section{Heritage}

Interest in heritage is seen as universal with many studies revealing high levels of interest in its preservation (McDonald, 2011). Heritage is regarded as "mandatory" and "fosters exhilarating fealties" (Lowenthal, 1990, p. 2). However, despite its undeniable presence and recognition in contemporary culture, heritage is often regarded as a broad and elusive concept. Prentice (1993, p.22) suggests "a series of overlapping and somewhat ill-defined market places" where visitors consume heritage attractions. More broadly, Nuryanti (1996, p. 249) defines heritage "as part of the cultural traditions of a society." Alternatively, Yale (1991) purports that heritage "really means nothing more than tourism centred on what we have inherited, which can mean anything from historic buildings, to art works, to beautiful scenery." Despite this apparent lack of agreement, much of the work on heritage explores its commercial application and is focused on the projection of heritage within a tourism framework.

However, alongside this broader cultural, commercial and tourism perspectives, it is also important to consider heritage in terms of its links to individual and collective identity. Howard (2003, p. 7) suggests that "people and their motivations define heritage." Thus while authenticity is based on the intrinsic value of the object or place, the meaning of heritage is 
derived by the user (Ashworth and Tunbridge, 1990). Heritage can therefore be understood as "a material and socio-psychological testimony of identity" (Park, 2010, p. 117) that provides “existential anchors” for consumers (Balmer, 2011, p.1383). In this sense, heritage is anything that an individual deems important enough to conserve for future generations (Howard, 2003, p. 6). In this paper, we expand on this relationship between heritage and identity by illustrating how local interpretations of heritage can be incorporated into marketing strategies that facilitate place identification.

There are various perspectives on consumers' ability to connect with their heritage. On the one hand, Otnes and Maclaran (2007, p.52) suggest that

given the mobility and fragmentation that define the postmodern world, consumers who wish to remain connected to their individual or collective heritages must often make concerted efforts and devote significant amounts of money and energy.

On the other hand, there has been emphasis on making heritage attractions more accessible to a broader audience, for example, Brown (1995, p. 74) spoke of "the abandonment of traditional display cases, silent contemplation and the aura of priceless authenticity, and their replacement with an anti-elitist emphasis on participation." Furthermore, Carnegie (2010, p. 232) highlights a blurring of the boundaries between museums and heritage spaces in that "people experience museum-related culture within society, both inside and beyond the museum," reflective of a more widespread "heritagized culture". By making heritage more accessible, it is not simply confined to tourist attractions, but becomes meaningful to a wider range of stakeholders, including local residents. In doing so, heritage becomes more relevant as a vehicle linking past, present and future (Miller, 1989; Balmer, 2011). We argue that the inclusion of local residents in heritage marketing strategies is an effective means of ensuring relevance is sustained. 


\section{Heritage and Place marketing}

Local interpretations of heritage can have an important role to play in place marketing because drawing upon a sense of place can both "revalidate and revitalise a local, national or international area" (Misiura, 2006, p. 14). This relationship between heritage and place marketing can serve a dual purpose; firstly as the basis for pursuing economic development and secondly, to facilitate place identification for residents (Kavaratzis, 2004). Most discussions focus on the former and highlight ways of improving and supporting the positive aspects of a place and diluting or obscuring negative aspects. In contrast, there is limited research which addresses place identification for residents and this is the gap which we seek to address. To better contextualise this perspective, we briefly review relevant literature within the place marketing domain.

We distinguish between 'place marketing' and 'place branding' which, although often used interchangeably, have key differences. Regarding place marketing, Kavaratzis (2005) outlines a concept emerging from humble promotional beginnings to encompass entire strategies of communication and integrated marketing approaches. Papadopoulous (2004) outlines a similarly pluralistic view showing: the range of contexts where place marketing is practised (domestically and internationally); the range of groups involved in place marketing, usually independent of each other and often independent of recognised local and national bodies; and, finally, the various ways in which place marketing is enacted which can range from systematic to more ad-hoc, instinctive applications.

Place branding, on the other hand, appears a more focussed form of place marketing and emerges from the growth and success of product branding. Despite a number of broad place branding themes (see Kavaratzis, 2005), the majority of place branding studies exist in the 'realm of destination brandings' and thus are tourism related (Kaplan et al. 2010, p.1290). This is in line with the predominant tourism focus within heritage discussions. In our study 
we adopt the term place marketing because community based activities (such as those we introduce in our research findings) are often contextually diverse, independent of recognised bodies and range from the systematic to the instinctive (Papadopoulous, 2004). Thus, place marketing seems a more inclusive term than the more focussed place branding.

In recent years one of the most prominent place marketing strategies is an emphasis on shopping and retail facilities (Warnaby et al, 2002). This approach is particularly evident for post-industrial towns and cities that attempt to transform their image from a place of production to a place of consumption (Hubbard and Hall, 1998). Potentially, this strong focus on consumption could erode any distinctiveness between towns and cities and detract from their uniqueness (Miles, 2010). While this strategy may advance economic development, an emphasis on consumption can be at odds with residents' priorities and consequently does not enhance place identification for residents (Hamilton and Trebeck, 2014). We explore an alternative to a retail focussed place marketing strategy that involves emphasising local heritage. This approach benefits from the involvement of local residents whose input leads to greater distinctiveness and place identification.

\section{Community Involvement in Heritage Marketing}

Millar (1989) suggests that a central goal when managing heritage is to ensure a balance between conservation (the needs of the resource) and tourism (the needs of the visitor). Once again, this neglects the needs of the local community which Nuryanti (1996) argues should also be central to heritage management. A community approach to the planning process has long been recognised as important (Murphy, 1985). Local people, argue Kavaratzis and Ashworth (2008, p.161) are "the most influential place marketers" and "they should be participants in all stages of formulating, designing and implementing a marketing strategy." Likewise, Timothy and Boyd (2003, p. 182) suggest that involving local residents in heritage development "is the most sustainable approach that can be taken." The interplay of local and 
market forces may prevent "insensitive commodification" that wipes out local heritage and culture (Teo and Yeoh, 1997, p. 210). However, this grassroots approach to heritage marketing and management is difficult to achieve in practice and there remains scant evidence of its implementation.

Ashworth and Graham (2005) discuss the tensions around the production of place identity, particularly in terms of the conflicting agendas of the multiple stakeholders involved. They suggest that the agendas of official public agencies tend to be prioritised: "the state and its agencies at many levels and scales appear to exercise an almost unchallenged control over art as expressed through the concept of heritage" (p. 87). Similarly, Aas et al. (2005) highlight the challenges in establishing effective communication channels between stakeholders, including official and unofficial interests. As a result, local community voices often remain overlooked and if anything, it tends to be representatives from local business that contribute to planning discussions which can result in an economic bias (Aas et al. 2005). There also remains an assumption that local residents do not have the necessary skills and resources to make a meaningful contribution to decision making and their input is therefore tokenistic and restricted to a superficial level (Jamal and Getz, 1995; Aas et al. 2005). In previous work, we disputed this perspective and demonstrated that community members have a wide range of resources and expertise that they draw on, from gardening knowledge to funding applications, to enhance the appearance and functionality of stations for tourism promotion (Hamilton and Alexander, 2013). Kirshenblatt-Gimlet (2006, p. 40-41) suggests that "the discourse of heritage...prioritises the rights of consumers to be able to access global heritage over the needs of those whose habitus is transformed into heritage." This paper provides an alternative perspective as we explore how the needs and opinions of the local community can take centre stage. We demonstrate how individuals get involved in heritage marketing and how 
organisations can encourage and engage with local communities. In the following section, we outline the contextual background of our study.

\section{Adopt a Station}

Adopt a Station is a community engagement scheme offered by First ScotRail, current holders of the rail franchise for all local, suburban and intercity routes within Scotland. Communities take part by adopting their local railway station. The activity has its roots in the community rail movement in England and since its launch in 2005, 200 stations (from 343) in Scotland have been adopted. Adoptions are found across the whole of the Scottish network in both rural and urban areas. Adoptions are varied and include: museums, bookshops, model railway clubs, community meeting rooms, art galleries, charity shops, toy libraries, small businesses and, most commonly, extensive gardening activity. The activities of adopters have been conceptualised as customer engagement behaviours which both augment and co-develop the station itself as well as influencing and mobilising other stakeholders to become involved in the wider value co-creation process (Jaakkola and Alexander, 2014).

The management and representation of heritage is a key theme throughout adoption projects but in varying ways. In some stations heritage constitutes the main part of the adoption (for example through heritage centres, museums and heritage murals and art), in other places heritage is one of a range of activities; finally, in some adoptions, the station's heritage is recognised by adopters and informs decisions on other activities (for example, colour schemes, choice of plants). Many of the stations feature listed buildings on the platform and, as such, heritage organisations take an interest in adopting, preserving and utilising these important community places.

Membership is straightforward, adopters are required to complete a simple application form and agree to basic health and safety regulations. Providing such regulations are adhered to, 
adopters have flexibility in their approach to the scheme. Both ScotRail and the communities play their part. ScotRail provides vacant rooms at the stations rent free, funds gardening activities and a ScotRail manager (in our research designated John Y) to oversee the scheme. Adopters contribute by paying any overheads, giving their time and effort and are responsible for sourcing additional costs involved in any restoration and customization of buildings, which may include obtaining funding from alternative sources.

\section{Method}

We adopted an ethnographic approach for data collection in order to situate behavior and meanings relevant to Adopt a Station through thick description (Geertz, 1973) that would allow a thorough appreciation of the uniqueness of the context. Initial access to the scheme was gained through John $\mathrm{Y}$ and data was collected over a two and a half year timeframe. The research team spent this extended time in the field visiting stations and witnessing first-hand the work of the communities. Data emerged from a number of sources which enabled us to cross-check and triangulate evidence between sources and methods.

After consultation with John Y, and a pilot study where 5 stations were visited, a data collection strategy emerged which targeted 19 adopted stations representative of the wide range of adoption activities. Our sample reflected the full diversity of activities included within the scheme, and, in this paper we focus on heritage related activity at stations which, as noted above, can range from the main focus of the adoption to an underlying constituent element. The stations of relevance to this study (and the activities therein) are summarised in table 1.

Insert Table 1 here 
All stations were visited by the research team who would spend anything from a few hours to several days on site. Our main source of data was in-depth interviews with station adopters, ScotRail staff and other stakeholders indirectly involved with the scheme. Interviews were held with individuals and groups depending on the nature of the adoption project. In total, over 100 respondents participated in the study; 40 participated in formal interviews which were digitally recorded with participants' permission. The interviews were broadly structured around the themes of origins and motivations, adoption activities, impacts and stakeholder relationships. The data equates to over 300 pages of transcribed material. Over 60 informal conversations were recorded as field notes. The use of visual sources of data was used to create a record of each station, over 850 photos were taken and over 6 hours of video footage of the stations was collected. This was predominately used to record adopters' feelings about the project in-situ but also the reflections of the research team. Textual data was also collected and this included excerpts from webpages (often created by the adopters), leaflets and brochures alongside newspaper articles and specialist books. We then utilised email interviews to gain understanding of a wider range of station projects, this elicited an additional 23 responses.

Data was analysed by each member of the research team using a process of open and then selective coding (Strauss and Corbin, 1998). The initial set of codes created by each researcher were then compared, filtered and refined using NVivo nine to finalize the codes. A sample of respondent quotes and attached codes were shown to colleagues for validity purposes. We then followed a hermeneutic approach to interpretation. Data relating to each station was interpreted independently to a gain a comprehensive overview of each station adoption. These were then compared and common patterns identified. In this paper our findings centre on three themes which are discussed in the next section. 


\section{Findings}

The first section of the findings offers some examples of heritage activities undertaken in the Adopt a Station scheme. The second section explores the benefits that arise from community participation with a particular focus on place identification. Our third section illustrates the features of Adopt a Station that encourage and support community participation.

\section{Community involvement in heritage activities}

Adopters undertake a wide range of heritage themed adoption activities. Our findings suggest that the railway station can become a stage where important moments in the town's history can be represented. The strong link between station adoption and heritage is recognised and facilitated by organisations such as the Railway Heritage Trust who can offer financial support for adoption projects that are in line with their objective of finding new uses for surplus station accommodation. The following observation from the chief executive of the Trust reinforces the importance of heritage to the railway industry:

We like our old buildings, we like our heritage as a country. From the point of view of the rail industry it is good politics to look after your heritage (Andy, Railway Heritage Trust)

One adoption example that focuses on "new use" for redundant spaces within the station is found at Wemyss Bay on the South West coast of Scotland. The station was built in 1903 as the rail/sea link between the nearby city of Glasgow and the popular tourist island of Bute. The station is designed with sweeping curves of metalwork and glass that link the railway terminus with the ferry pier (see figure 1). The adopters" aim "is to celebrate having this grade-A listed structure in our midst, to become a local resource, and a place of interest to visit".

\footnotetext{
Insert Figure 1 Here
} 
Adopters achieve this aim through various activities including a community allotment, bookshop and exhibition space which has permanent displays of historical station photographs and original schematic diagrams of the station. Adopters also create extensive floral displays aimed at recreating the way the station used to look. The efforts of adopters have transformed what was described as a "dismal" and "uninviting" station into a place that the local community can be proud of. Nancy, chairperson of the Friend's Association at Wemyss Bay observes that adoption has "The restoration of flowering plants within the station has given great pleasure to the travelling public, who frequently go out of their way to express their appreciation."

Floral displays are also used for commemorative purposes, for example, the $70^{\text {th }}$ anniversary of the evacuation from Dunkirk in 2010 was marked by a volunteer who recreated:

in plant material, the crest of the Waverley, the paddle steamer which had played a vital part in the evacuation of troops from the beaches of Dunkirk. Like many people, he remembers the handsome display cases which used to stand on the walkway down to the pier, and which contained original paddlebox crests (Friends of Wemyss Bay Station, AGM Report).

Holidays and days trips in this area became increasingly popular throughout the 20th century and as a result the station is seen as representative of this unique local heritage as the last remaining Edwardian station in Scotland with both a rail and pier connection. In the past, many Scottish families would have passed through the station to reach the ferry connection to the Isle of Bute and this nostalgic significance is another motivation for preserving the station:

it has a folk memory for so many people... with the ferry connection they associate the one with the other, going on holiday, coming down to the sea, escaping Glasgow, getting away...that is really what struck me, the number of people [who] just remember and associate it with pleasure and excitement and they want to see it continue, they don't want it to be demolished and rot away (Nancy).

The growth of international holidays in the latter part of the $20^{\text {th }}$ century resulted in a steep decline in tourism in the area. Hence, much of the adopters' activities are focused around the 
needs of the local community whilst retaining the original features which made the station unique and preserving its historical significance. This included negotiating with the rail franchise operator to retain the original colour scheme of the station as opposed to the corporate colours used in other stations. As Paul, one of the adopters explained, "the fact that it does not wear branded colours should make it a trophy, it should be something outstanding, something remarkable." The local community involvement enables accurate preservation of the station and prevents any "insensitive commodification" (Teo and Yeoh, 1997, p.210) from the firm. Consequently, the unique heritage of the station is sustained in a way that remains relevant to a much wider range of stakeholders than just tourists.

Another heritage use for vacant accommodation is found at Cupar in the East of Scotland where several disused rooms have been transformed into a heritage centre, something that the adopters believe has long been missing from the town:

If you look at the local paper from 10-15 years ago you will see that various people at different times have demanded or asked for a museum in Cupar.... there is a continuous thread of people wanting and wanting... but it took the current Committee to move it on and to be able to manage the applications and have the foresight to see what might happen with it. It is an ideal little situation because the station is so good because everybody that is travelling in and out on the trains does see it, so rather than have an empty shop, say up a back street, you have got a very visible place (Bruce, Cupar Heritage).

Alongside this, the local allotment group maintain vegetable tubs to reflect the agricultural heritage of the local area and the station is brightened by hanging baskets, plants and, on occasions, edible plants which passengers are encouraged to take. The opening of the heritage centre was a long process and not without significant effort from the adopters to secure funding. The outcomes of this effort were viewed as offering significant benefits:

I think what has happened is we both win, ScotRail and ourselves because we have got a nice facility and they have got a place that was not looked after, was in worse condition, an empty house, bad condition, which looked dingy and dark. Now it is fresh, it was painted outside, and inside, it has been totally transformed so forever more that will be a renovated place. So they have benefited from this lovely stone building that is here in Cupar has now got a little appendage that is no longer decaying (Chairman, Cupar Heritage Trust). 
Unlike Wemyss Bay it is the location of the station that is attractive to adopters which makes the heritage activity more accessible by immersing it within an everyday lived environment (Carnegie, 2010). Heritage therefore becomes integral to ongoing community activity.

Another station with a strong heritage focus is Glenfinnan in the West Highlands of Scotland. The location is significant as it is closely associated with the Jacobite Rebellion of 1745 being the spot where 'Bonnie Prince Charlie' landed from exile. Glenfinnan station is also one of the few remaining Swiss Chalet style stations on the West Highland line.

\section{Insert Figure 2 Here}

The Glenfinnan adoption comprises a station museum which tells the story of the West Highland Railway and its construction and development over the past 100 years, a bunkhouse converted from a 1958 railway carriage that now provides accommodation for 10 people, a station tearoom, located within another carriage, and a historical water tank and snowplough. The station has a friends association which contribute to the adoption through tending the flowers, working in the museum and developing other tourism infrastructure around the station including hiking paths and a miniature railway. This activity is led by John and Hege, a couple who live in the station cottage and run the museum. The couple were instrumental in securing funding of $£ 450,000$ to refurbish the main station building which houses the museum. The station is described by one of the adopters as a "hub of activity" within the village.

Glenfinnan is a popular tourist destination because of its location on the West Highland Line (voted the best railway journey in the world for 3 consecutive years by Wanderlust travel magazine). From May to October, the Jacobite steam train stops daily in Glenfinnan carrying up to 350 tourists. Although the heritage offering at this station is more focused on tourists 
than other stations in our study, the activities are managed by local community residents and are not under corporate control. In recent years the station has also gained increased notoriety because of the connection with Harry Potter. The Jacobite steam train featured as the "Hogwart's Express" in the film franchise. However, to our interviewees this could also detract from the heritage of the area:

they come from everywhere, not all of them dressed up but there are tourists from all over the world. They are whizzing through the station saying, where is the Harry Potter bridge? This in a way is good that it has attracted attention but in other ways it is sad that is all that they are looking for and that is all they see when they visit this fantastic area (Hege).

The station adoption activities, through the museum and other historical artefacts, allow the adopters to emphasise and promote an image of their community that goes beyond surface level movie fascination. Alongside the museum a disused signal box has been converted to an educational facility with an audio-visual studio and reading room. An emphasis on these activities creates a stronger heritage focus, presented as an alternative to the more recent, and perhaps transient, attention created by the Harry Potter film franchise. Without local community involvement, place identity could be overshadowed by the activities of the Harry Potter fan community who detract attention away from local heritage.

Adapting redundant accommodation is not the only way of incorporating a heritage focus at stations. An interesting alternative can be found in Invergordon in the far North East of Scotland where the station forms part of a wider regeneration initiative called 'Invergordon Off The Wall', a project bringing the heritage of Invergordon to life through a series of murals on the side of buildings that transform the town into an "outdoor art gallery". The project aim was to "regenerate and enhance Invergordon in a way that promotes community involvement and a sense of local identity". The station mural is entitled "The Long Goodbye" and depicts the departure of the Seaforth Highlanders from the station in 1939 and their subsequent war history including capture at Dunkirk and captivity in Germany. For the 
adopters and representatives of 'off the wall,' adopting the local station was a critical element of the wider community activity as it represents a particularly poignant moment in the town's history as only one in ten of the Seaforths who set out ever returned home. The mural (see figure 3) was unveiled in 2007 and stretches the entire length of the station. It includes many authentic and life size elements of the day including the station master, his cat and some of the soldiers who were part of the battalion.

\section{Insert Figure 3 Here}

Community involvement was central in the design of "The Long Goodbye" mural, particularly for those who had a personal connection with these historic events but also for local school children who designed World War 2 themed posters. Alongside research at the Imperial War museum, survivors, widows and relatives of the Seaforths provided the artist with photographs and memories.

Yes we had a Heritage event... anybody who was interested could come along with pictures and stories, we all sat at different tables and they gave us the wee stories about the pictures that they had. Then we had a Heritage Ceilidh [dance] as well so there was lots of information gathered before the mural [was started] (Wilma, Station Adopter).

The mural is colourful and eye-catching but, as a result of community consultation, retains a sense of authenticity as constructed by the local community. Goulding (2000) found that a desire for authenticity was an underlying motivation for visitors to heritage attractions and the mural appears to respond to Goulding's (2000) recommendation of balancing accurate representations which meets the needs of the community and visitor engagement which meets the needs of tourists. Like Cupar, heritage activities can be found elsewhere in the town but the station context is important because it brings heritage to one of the town's main gateways making it more accessible to a broader range of people. As passengers arrive via train or wait at the platform, they have the opportunity to interact with the mural. 
Sometimes traditional 'heritage-themed' places lack accessible consumer appeal. Kotler and Levy (1969, p.11) argue that for many, museums are "cold marble mausoleums that house miles of relics that soon give way to yawns and tired feet." Although there has been significant progress with museum marketing and presentation since this publication, this image may still predominate. In response, authors have discussed repositioning strategies that can be employed to help museums appeal to new audiences, for example Jafari and Taheri (2013, p.13) discuss how a museum can encourage consumers to "engage in meaningful narratives of life". We offer an alternative perspective whereby Adopt a Station can facilitate bringing local heritage outside of the museum to community places which residents and visitors pass through on a daily basis. Crucially, the heritage activities described above are determined and delivered by the community with often very limited corporate involvement. This self-determination and the flexibility of delivery were attractive to the community and, central in facilitating place identification.

\section{Community heritage marketing and place identification}

There are clear heritage-related benefits associated with community involvement at the stations, in terms of facility improvements and preservation, custodianship and the positive relationships built with communities:

I think that the benefits are quite clear that you get a degree of ownership, you get some extra care being put into the place and it looks as if it is being looked after...I cannot imagine there are any downsides from any of that. (James, Passenger Focus)

Through occupation the station is afforded greater protection, something recognised by the Railway Heritage Trust, 'if it is lived in, then it is loved, it is as simple as that, any building that has got people in it is in a better state” (Andy, Director, Railway Heritage Trust). All stakeholders agreed that better maintained, occupied buildings were preferable over empty rooms that are left to decay. 
Existing literature prioritises the economic impact of place marketing strategies at the expense of social impact on local residents. In the remainder of this section we address this imbalance by focusing on the ways in which participation in Adopt a Station supports the construction of individual and collective place identification. Adopters gain various personal benefits including enjoyment, empowerment, a sense of achievement and pride in preserving the town's heritage for future generations. Equally, respondents often demonstrated a strong emotional connection with the station. Hege at Glenfinnan explained:

Many of the other station [buildings] ... have been demolished, which is rather a shame and that was John's first trigger of interest in the station I suppose. It was looking quite horrible when he came, it was a Listed Building and it broke his heart I think to see it like that and he wanted to do something about it (Glenfinnan).

For adopters, stations become an important part of the extended self (Belk, 1998) with strong emotional and affective attachments connecting adopters to the stations. This further supports the effort and commitment adopters are willing to offer. Drivers of this attachment are varied. For some adopters, such as John, it is due to a history of employment within the railway industry. For others, place attachment may be strengthened by memories of childhood holidays (Wemyss Bay) or associated with poignant moments in one's personal history (saying goodbye to a loved one at Invergordon station). In each instance, heritage becomes important because it is personally meaningful (Howard, 2003).

At a collective level some of the towns and villages where station adoption is prominent are located in areas of industrial decline or depopulation. Other adoptions are found in unmanned stations. What Adopt a Station offers is a way to "restore life" to these communities and bring back a "sense of pride" in the local area.

I think it is about the community having a say in what its local gateway looks like. It is about owning that, it is about taking control, it is about putting something back, it is about community spirit involving folks and being able to project a little of the community into the station (John Y). 
On occasions adopting the railway station fits in with wider community agendas on civic improvements. At Stonehaven near Aberdeen the Stonehaven Horizons Group created a series of posters promoting Stonehaven and its many heritage attractions which were displayed at the station:

We are not looking for compliments; we just want to enhance the thing ourselves because it is a matter of civic pride as far as we are concerned ... I think that it gives a good impression of the town, people passing through and people stopping here, these things are important (Alan, Stonehaven).

Through displaying their heritage the adoption groups are able to "communicate their identity, construct their sense of place and create shared memories" (Crooke, 2005, p. 226). Adopt a Station facilitates individuals and communities in achieving or recapturing place identification. We continue by exploring how the management of the scheme facilitates each community's unique approach.

\section{Facilitating community participation through Adopt a Station}

One of the reasons behind the growth and success of the scheme was its ease of use. The application process requires the completion of a simple form and as long as activities at the station meet health and safety regulations (described by one participant as 'just good common sense') and do not interfere with the running of the railway, adopters have flexibility in relation to their activities. Within a very quick time period groups are invited to "move in" to the stations:

It sounded easy, normally when you hear about some of these schemes, especially in the past with the railways it is full of bureaucracy, you cannot do this and you cannot do that, and reading it... it sounded really flexible and easy...so I thought maybe give this a try (Peter, Whitecraigs).

We observed this first-hand at a ScotRail event and witnessed potential adopters who were interested in taking over rooms in a station being told "just move in, if you move in things will begin to happen". This approach puts onus on the community groups to be proactive in setting up adoptions. For example, at one station John Y explained to us that he met with 
potential adopters and showed them which rooms were available, the following week he was invited back to meet with 'the committee' in one of the vacant rooms which had already been converted to a meeting space. In others stations the setting up of charitable groups further legitimised their involvement. For example, the 'Friends of Wemyss Bay Station' (with over 250 members) is comprised of local residents but also includes members from Australia and China who perceive the station to be "unique" and wish to see its heritage preserved for future generations. This affords communities a sense of ownership or as one adopter put it, made them feel like "custodians" of the station. Although ScotRail have all the usual trappings of a brand (colour scheme, logo etc.) they appear to recognise the need to legitimise communities to change the appearance of stations beyond the corporate standard. ScotRail recognised that a consistent product (whilst important) is "potentially a bit dull" and that by supporting a range of adoptions communities can "inspire and explore in their own way" (John Y).

This freedom allows communities to celebrate heritage beyond potentially restrictive corporate control. John Y observed how engendering this sense of ownership was essential within a landscape of frequent change where only local residents remain constant. The temporary and transitory nature of railway stakeholder involvement means that is only the local residents who have the long-term knowledge of heritage that can revalidate and revitalise a sense of place (Misiura, 2006).

Adopters in this study also suggested that this ease and flexibility was further enhanced by the ScotRail manager responsible for the recruitment of adopters and the management of the scheme (John Y). Throughout our study he was seen as a central figure who acted as a buffer for adopters and, on their behalf, negotiated with other stakeholder groups involved in the railway industry: 
If you have got other minds trying to restrict you or push you in a different directions then it is not that much fun anymore. I suppose that is what [John Y] is so good at, he just allows you to get on (Hege, Glenfinnan).

John Y acts as a network builder and facilitator; he organises an annual lunch to bring together adopters from across Scotland and passes on information about adoption success stories (or as one participant describes, "spreads the Gospel.") John Y's work and commitment is recognised by all adopters to the extent that some question whether or not Adopt a Station would be as successful without his involvement:

"He is the encyclopaedic brain behind the scheme... yes it is his encouragement and his resilience that has carried the scheme forward, he is almost irreplaceable in terms of the scheme itself and long may he continue." (Sonia, Arisaig and Mallaig)

"I would say he is the most important thing in the whole process because he is such an advocate for the whole thing and he really does work bloody hard." (Steve, Bridge of Orchy)

The flexibility and user friendly nature of Adopt a Station means that heritage activities can flourish more or less untroubled by corporate interference. Unlike previous research where community contributions are viewed as tokenistic and superficial (Jamal and Getz, 1995; Aas et al. 2005), our research suggests that it is the freedom to promote heritage in a way of their choosing and the freedom to do so within an important community location that is the main contributor of success. This empowering approach of the firm favours local forces who, in turn, work to prevent the dilution of local heritage (Teo \& Yeoh, 1997).

\section{Conclusions}

"A railway station mirrors the soul of the place where it is located" (Kopperud, 1998, $p$. 235)

In this paper we contribute by offering insight into successful heritage-based community activity which has to date been seen as important but without empirical studies to demonstrate its application. In our study, participants not only promote their heritage to the outside world (Hamilton and Alexander, 2013) but also regenerate redundant space in station 
buildings which adds value to their local communities by prioritising their heritage needs as an internal market. Our research shows how towns and villages across Scotland are marketing their uniqueness through local heritage by celebrating important moments in the history of a community or bringing its collective heritage into the public domain. As a result, communities are able to portray a meaningful heritage message to the local community as well as visitors. This is an important contribution because recent literature tends to focus on the economic impact of place marketing rather than place identification for local residents, arguably the most important stakeholder group.

The promotion of local heritage offers a contrast to the theme of consumption which often dominates the agendas of place marketers, policy makers and planners; an approach which is accused of eradicating distinctiveness (Miles, 2010). The diversity of adoption projects, even within our relatively small sample, demonstrates that heritage marketing offers an alternative route that promotes uniqueness. Each station adoption is driven by different community motivations; sometimes it is the desire to preserve the unique features of station buildings that is central to activities and sometimes the station is merely seen as an effective platform to improve access to heritage. In early works on community involvement in heritage management Murphy (1985, p.151) sought a shared vision and focus on "the community's heritage and culture in the development of the tourism product." Adopt a Station allows this shared vision to be realised. Whatever their motivation, our context facilitates the showcasing of heritage that is meaningful to community residents. As such, we reveal how community heritage marketing can aid the construction and maintenance of both individual and collective identity.

As well as celebrating community heritage, there is also emphasis on ensuring its future survival. For example, John and Hege at Glenfinnan are aiming to create a business that can be continued after their retirement. In Invergordon we witness the involvement of secondary 
school age children in the mural design (and a local brownie group are responsible for one of the flower beds) and this intergenerational communication ensures that important moments in a community's history are not forgotten. At Cupar, preservation of artefacts and information was a key motivation in setting up the heritage centre, facilitated by the scheme. Adoption projects are not, therefore, simply about looking back but also creating future resources, fitting with Balmer's (2011) tripartite temporal approach to heritage.

Our research also illustrates how local residents can become "influential place marketers" (Kavaratzis and Ashworth, 2008, p. 161) by effectively promoting their heritage without any formal connections to official organisations and with only basic support from the partner firm. The variety of different approaches to displaying heritage in our study suggests that the value of community involvement lies in the unique interpretation each community may have and firms may, therefore, have to sacrifice a share in any vision in exchange for good relations with the community. We suggest that it is the freedom offered to the community and the resulting control and sense of ownership gained that allows community management of the heritage message to flourish.

Within our context, the role played by the firm was critical to the success of the scheme. The firm knows when to get involved when facilitating community heritage activity and making relevant connections between stakeholders but also appreciates the value of doing very little, but doing it very well. This, seemingly, highly flexible approach served two purposes: firstly, it demonstrated the firm's willingness to be involved; secondly, it demonstrated the strength of feeling around the community and their levels of motivation. In our context, this "if you offer it, they will come" approach appears to have paid dividends. Between 2009 and 2013 adoptions rose from 85 to 200 and now nearly two thirds of stations are adopted with very few projects viewed as failures. This success appears in total contrast to existing literature on community involvement in place marketing. Unlike previous work that questions the 
usefulness of community involvement (Aas et al. 2005, Simmons, 1994, p.106), we show that local residents can make a positive contribution that benefits themselves and the partner organisation. Additionally, unlike previous studies where community residents have only tokenistic involvement (Holcomb, 1999, Ashworth and Graham, 2005), we have discussed a case where local residents are in fact the main driving force in heritage marketing. Our study therefore raises several important implications.

We suggest that while the potential for local heritage to be transformed into a marketable tourist attraction seems not to be in question there is a necessity that the results reflect the importance, sense of meaning and attachment that local residents feel about the heritage and that they recognise themselves in the results. Relating specifically to urban place marketing, Warnaby et al. (2002, p. 896) highlight "a complex interlocking web of formal and informal relationships" including those responsible for inward investment, retail provision etc. Our study implies that local residents should be integrated into this web. The latent potential residing in communities should not be underestimated and initiatives which empower residents should be prioritised to capitalise on their knowledge, passion, skills and expertise. Finally in line with a policy context that focuses on making heritage more accessible, we observe how bringing heritage outside the museum space into key places used by local residents can support this aim. We provide one insightful example that implies museums are not the only venues where interpretations of heritage can be presented. Other examples may include the display of artwork in retail units or exhibitions housed in cafes and restaurants. 


\section{References}

Aas, C., Ladkin, A. and Fletcher, J. (2005), "Stakeholder collaboration and heritage management," Annals of Tourism Research, 32, pp. 28-48.

Ashworth, G. J. and Graham, B. (2005) Senses of Place: Senses of Time. Ashgate, Aldershot.

Ashworth, G. J., and Tunbridge J. E. (1990) The Tourist-Historic City. Belhaven, London

Balmer, J.M.T. (2011), “Corporate heritage identities, corporate heritage brands and the multiple heritage identities of the British Monarchy", European Journal of Marketing, Vol. 45, Iss. 9, pp. $1380-1398$.

Belk, R. W. (1988), "Possessions and the extended self", Journal of Consumer Research, Vol. 15, No. 2, pp. 139-168.

Brown, S. (1995), Postmodern Marketing, Routledge, London.

Carnegie, E. (2010), "Museums in Society or Society as a Museum? Museums, Culture and Consumption in the (Post) Modern World," Kerrigan, F. and O'Reilly, D. (Eds.), Parcelling the Past: Selling Heritage in the Modern World: New Directions in Arts Marketing, Taylor Francis, London, pp. 231-239.

Crooke, E. (2005), "Community heritage and place making in Northern Ireland", in McCarthy, M. (Ed), Ireland's Heritages: Critical Perspective on Memory and Identity, Ashgate, pp. 223234.

Geertz, C. (1973), "Thick description: Toward an interpretive theory of culture", Culture: critical concepts in sociology, Vol. 1, pp. 173-196.

Goulding, C. (2000),"The commodification of the past, postmodern pastiche, and the search for authentic experiences at contemporary heritage attractions", European Journal of Marketing, Vol. 34, Iss: 7, pp. 835 - 853.

Hamilton, K. and Alexander, M. (2013) "Organic Community Tourism: A Cocreated Approach,” Annals of Tourism Research, Vol. 42 (July), pp. 169-190.

Hamilton, K. and Trebeck, K. (2014) Marketing for Mortality? The Scottish Case and the Humankind Index in Humanistic Marketing, ed Richard J Varey, Palgrave Macmillan Series on Humanistic Management, pp. 84-97.

Holcomb, B. (1999), "Marketing cities for tourism", in Judd, D.R. and Fainstein, S. (Eds), The Tourist Place, Yale University Press, New Haven, CT, pp. 54-70. 
Howard, P. (2003), Heritage: Management, Interpretation, Identity. Continuum International, New York.

Hubbard, P. and Hall, T. (1998) "The Entrepreneurial City and the New Urban Politics", in Hall, T. and Hubbard, P. (Eds), The Entrepreneurial City: Geographies of Politics, Regime and Representation, Wiley, Chichester, England, pp. 1-23.

Jaakkola, E. and Alexander, M. (2014), "The Role of Customer Engagement Behavior in Value CoCreation: A Service System Perspective," Journal of service research, Vol. 17, Iss 3, pp. $247-$ 261.

Jafari, A. and Taheri, B. (2013), "Nostalgia, reflexivity, and the narratives of self: reflections on Devine's “Removing the rough edges?", Consumption Markets \& Culture, DOI:10.1080/10253866.2013.776312

Jamal, T. and Getz, D. (1995). "Collaboration theory and community tourism planning," Annals of Tourism Research, 22, 186-204.

Kaplan, M. D, Yurt, O. Guneri, B. and Kurtulus, K. (2010),"Branding places: applying brand personality concept to cities", European Journal of Marketing, Vol. 44, Iss. 9, pp. 1286 1304.

Kavaratzis, M. (2004), "From city marketing to city branding: Towards a theoretical framework for developing city brands", Place Branding, Vol. 1, Iss. 1, pp. 58-73.

Kavaratzis, Mihalis (2005) Place Branding: A Review of Trends and Conceptual Models, The Marketing Review, 5, 329-342

Kavaratzis, M. and Ashworth G.J. (2008), "Place marketing: How did we get here and where are we going?" Journal of Place Management and Development, Vol. 1, No. 2, pp. 150-165.

Kirschenblatt-Gimblett, B. (2006), "Exhibitionary complexes" in Karp, I., Kratz, C.A., Szwaja, L. and Ybarra-Frausto, T. (eds.) Museum Frictions: Public Culture/Global Transformations, Durham: Duke University Press.

Kopperud, G. (1998). The Time of Light. London: Bloomsbury.

Kotler P. and Levy, S. J. (1969), "Broadening the Concept of Marketing", Journal of Marketing, Vol. 33, No. 1, pp. 10-15.

Kozinets, R. (1999), "E-Tribalized Marketing?: The Strategic Implications of Virtual Communities of Consumption", European Management Journal, Vol. 17, No. 3, pp. 252-264.

Lowenthal, D. (1998), The Heritage Crusade and the Spoils of History, Cambrige, Cambridge University Press. 
McDonald, H. (2011), "Understanding the antecedents to public interest and engagement with heritage", European Journal of Marketing, Vol. 45, Iss 5, pp. 780 - 804.

Miles, S. (2010), Spaces for Consumption, London, Sage.

Millar. S (1989). "Heritage Management for Heritage Tourism,” Tourism Management, March, pp. 914.

Misiura, S. (2006). Heritage Marketing. Elsevier, Oxford.

Murphy, P. (1985), Tourism: A community approach, Methuen.

Nuryanti, W. (1996), "Heritage and postmodern tourism," Annals of Tourism Research, Vol. 23, Iss. 3, pp. 249-260.

Otnes, C. and Maclaran, P. (2007), "The consumption of cultural heritage among a British Royal Family brand tribe", in Kozinets, R., Cova, B. and Shankar, A. (eds.), Consumer Tribes: Theory, Practice, and Prospects. Elsevier/Butterworth-Heinemann, p. 51-66.

Papadopoulous, N (2004) Place Branding: Evolution, Meaning and Implications, Place Branding, $1(1), 36-49$

Park, H. Y. (2010), "Heritage Tourism: Emotional Journeys into Nationhood", Annals of Tourism Research, Vol.37, Iss. 1, pp. 116-135.

Prentice, R. (1993) Tourism and heritage attractions. Routledge, London.

Simmons, D. G. (1994). "Community participation in tourism planning", Tourism Management, Vol. 15, pp. 98-108.

Strauss A. L., Corbin J. M., 1998 Basics of qualitative research: Techniques and procedures for developing grounded theory. Sage Publications Inc. Thousand Oaks, CA

Timothy, D.J. and Boyd, S.W (2003), Heritage Tourism. Pearson, UK.

Teo, P. and Yeoh, B. S. A. (1997), "Remaking local heritage for tourism", Annals of Tourism Research, Vol. 24, pp. 192-213.

Warnaby, G., Bennison, D., Davies B.J. and Hughes, H. (2002), "Marketing UK Towns and Cities as Shopping Destinations", Journal of Marketing Management, Vol. 18, No. 9-10, pp. 877-904.

Yale, P. (1991) From tourist attractions to heritage tourism. ELM publications, Huntingdon. 


\begin{tabular}{|c|c|c|}
\hline Station & Adoption & Heritage and Other Activities \\
\hline Arisaig & Individual Adopter & $\begin{array}{l}\text { The most 'Westerly Station' in the UK. The Jacobite Steam Train stops daily, and station is maintained and } \\
\text { gardening designed to reflect heritage tourism activity. Also features community meeting room. }\end{array}$ \\
\hline Bridge of Orchy & West Highland Bunkhouse & $\begin{array}{l}\text { Gardening and a bunkhouse on the station platform. 'Swiss Chalet' style building and Signal box grade 'B' listed } \\
\text { buildings.* }\end{array}$ \\
\hline Crianlarich & Crianlarich Station Tearoom. & $\begin{array}{l}\text { A station tearoom which has been serving meals since 1900. Interior features information boards, display of } \\
\text { original meal order telegrams from 1900s. Flowers on station platform }\end{array}$ \\
\hline Cupar & $\begin{array}{l}\text { Cupar Heritage/'Cupar in } \\
\text { Bloom’ }\end{array}$ & $\begin{array}{l}\text { A heritage centre located in a disused flat above the ticket office. Flowers and 'edible garden' on station } \\
\text { platform.* }\end{array}$ \\
\hline Glenfinnan & Friends of Glenfinnan Station & $\begin{array}{l}\text { Museum in the old ticket office, an educational centre in the signal box, a bunkhouse and tearoom (both in disused } \\
\text { railway carriages), refurbished historical water tank, snow plough, landscaping and flowers.* }\end{array}$ \\
\hline Invergordon & $\begin{array}{l}\text { Invergordon 'off the wall' plus } \\
8 \text { gardening groups }\end{array}$ & $\begin{array}{l}\text { Station mural 'The Long Goodbye' depicts the departure of the Seaforth Highlanders from the station in } 1939 \text { and } \\
\text { subsequent war history including capture at Dunkirk and captivity in Germany. Also extensive gardening. }\end{array}$ \\
\hline Kinghorn & Individual Adopter & Former station masters house and flat are converted into an art gallery and studio; flowers.* \\
\hline Mallaig & Individual Adopter & Gardening, hanging baskets and informal tourist information. Final stop for Jacobite Steam Train. \\
\hline Maxwell Park & $\begin{array}{l}\text { The Pollokshields Heritage } \\
\text { Trust }\end{array}$ & $\begin{array}{l}\text { Grade 'B' listed Victorian 'vernacular' style station features Trust led community meeting room and exhibition } \\
\text { space; flowers maintained on platform. }\end{array}$ \\
\hline North Berwick & North Berwick in Bloom & Flowers maintained on platform. Flower beds reflect fishing heritage of town. \\
\hline Pitlochry & $\begin{array}{l}\text { 'Pitlochry in Bloom' and } \\
\text { 'Pitlochry Station bookshop' }\end{array}$ & $\begin{array}{l}\text { Refurbished station buildings, Victorian footbridge and drinking fountain. Flowers and Pitlochry Station } \\
\text { Bookshop* }\end{array}$ \\
\hline Stonehaven & Stonehaven horizon group & Flowers and commissioned posters which advertise town's heritage and tourist facilities. \\
\hline Uddingston & Uddingston Pride & Extensive Flowers and station café featuring pictures of original station features. \\
\hline Wemyss Bay & $\begin{array}{l}\text { The Friends of Wemyss Bay } \\
\text { station }\end{array}$ & $\begin{array}{l}\text { An award winning second hand bookshop, exhibition space featuring displays of station heritage, a huge array of } \\
\text { flowers including heritage themed displays, mini-allotments for retired residents.* }\end{array}$ \\
\hline West Kilbride & $\begin{array}{l}\text { West Kilbride Community } \\
\text { Council }\end{array}$ & $\begin{array}{l}\text { Flowers by community council and 'Chu-Chu's' restaurant (painstakingly restored to replicate original station } \\
\text { interior) }\end{array}$ \\
\hline Whitecraigs & Individual Adopter & Award winning flowers and gardening surround traditional station building. \\
\hline
\end{tabular}

* Adoption part sponsored by Railway Heritage Trust 


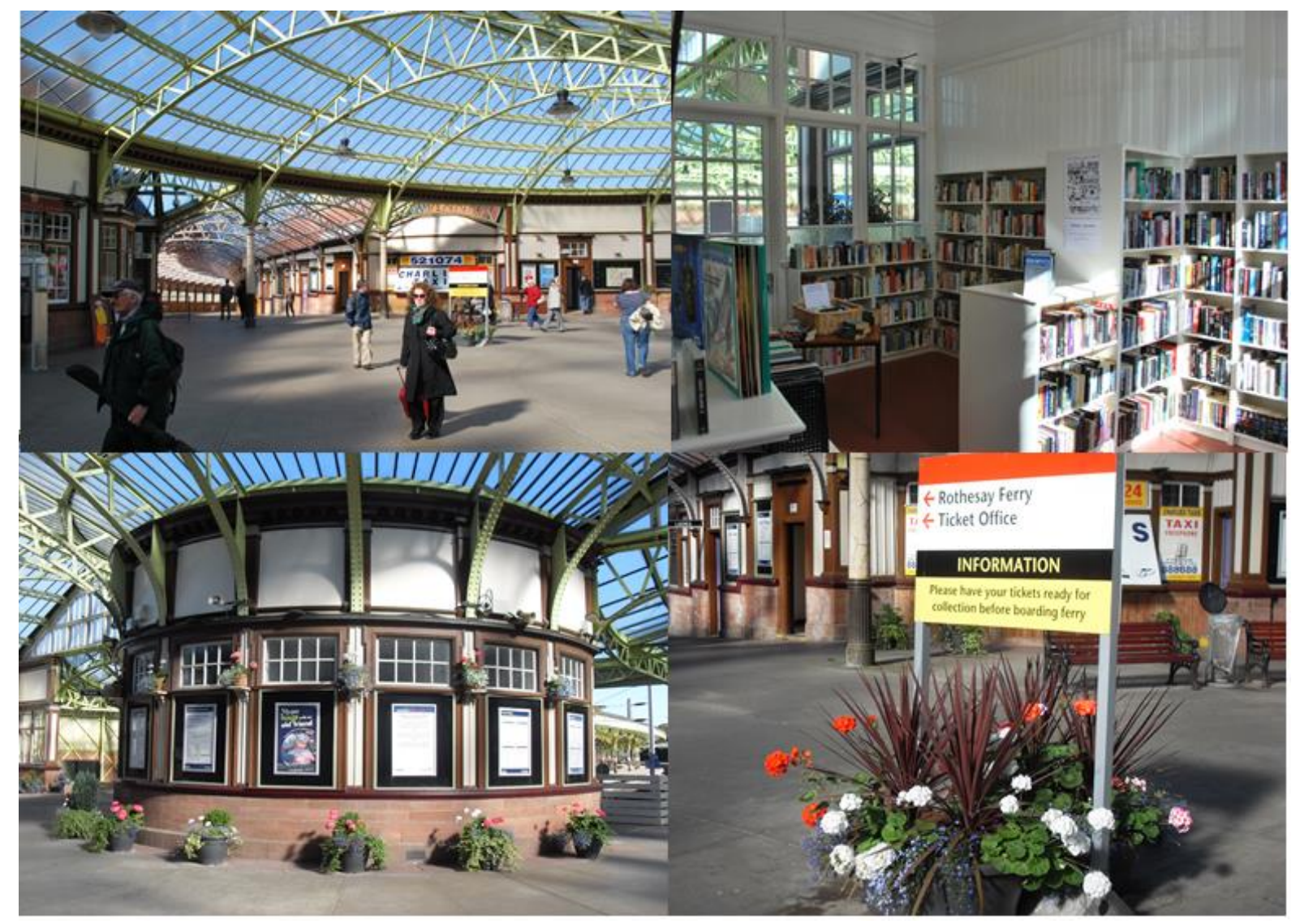

Figure 1 - Wemyss Bay Station 


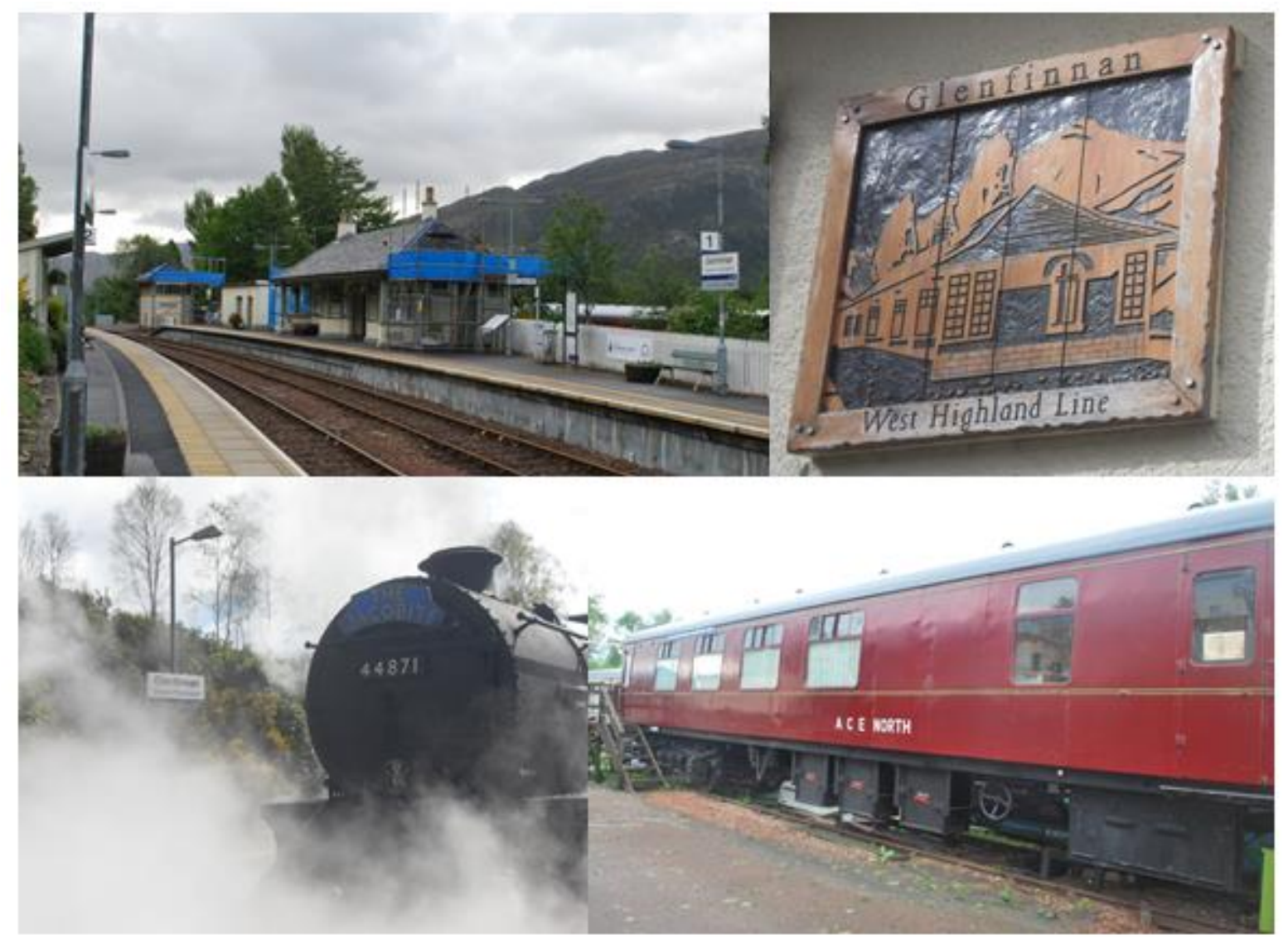

Figure 2 - Glenfinnan Station 


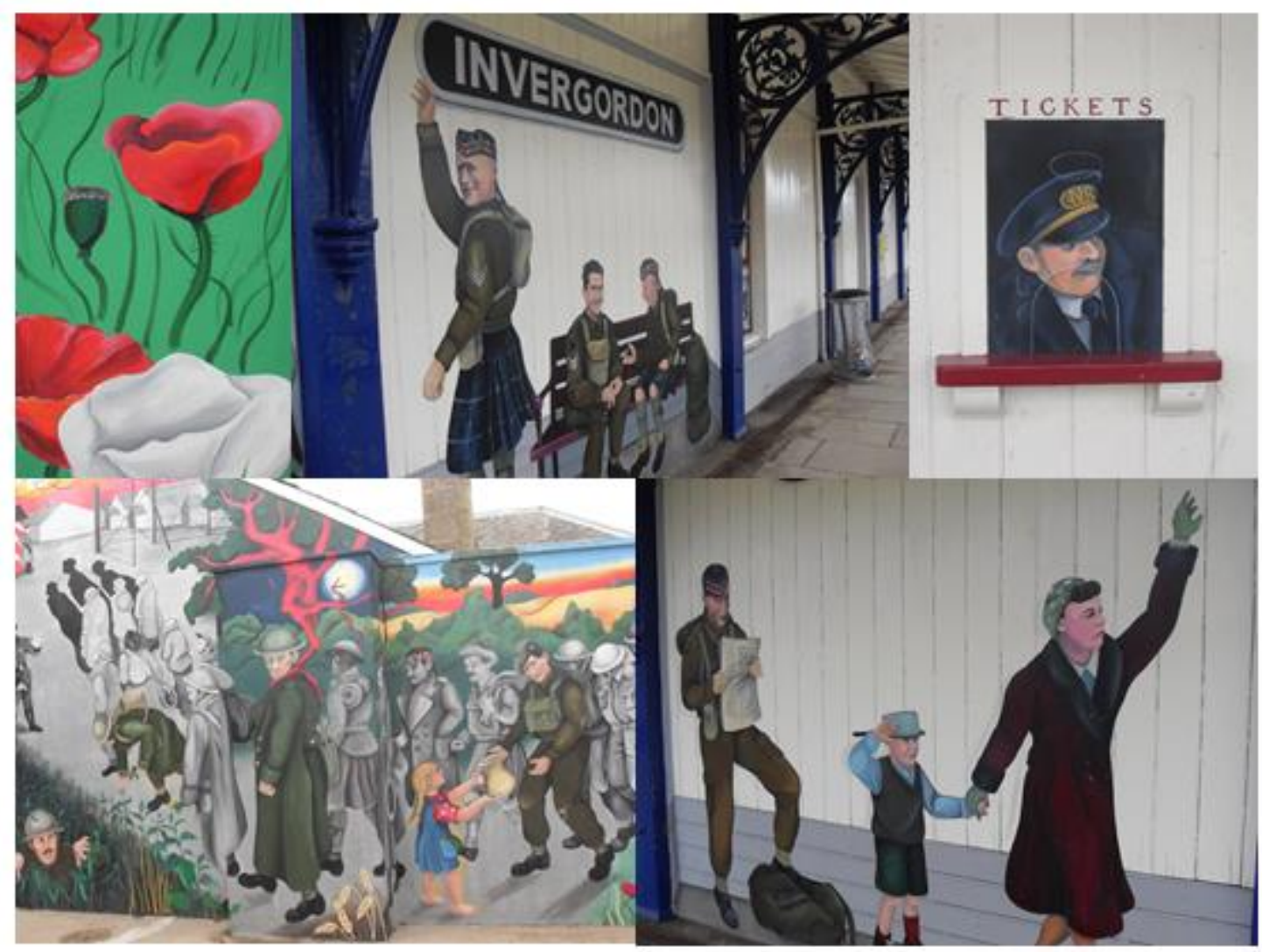

Figure 3 - Invergordon Station 